\title{
HETEROSIS AND QUANTITATIVE INHERITANCE
}

\author{
B. I. HAYMAN \\ Applied Mathematics Laboratory, D.S.I.R., Private Bag, \\ Christchurch, New Zealand
}

Received 21.vii.6o

Four common explanations of heterosis are overdominance, the accumulation of favourable dominants, interaction between non-allelic genes and heterozygosity per se. These are not mutually exclusive and most geneticists support more than one of them (Grafius, r959). Watkin Williams (r959) has added a fifth to this list, the somatic multiplication of additively-controlled component sub-characters, and at the same time has criticised the explanation by gene interaction.

To be justified, Williams' explanation should satisfy two criteria. Is it more useful than any of the previous explanations? Does it show that

TABLE 1

Components of fruit yield

\begin{tabular}{|c|c|c|c|c|}
\hline & & $\begin{array}{l}\text { Component } \mathrm{A} \\
\text { fruit number }\end{array}$ & $\begin{array}{l}\text { Component } \mathrm{B} \\
\text { fruit weight }\end{array}$ & Yield \\
\hline Parent $\mathrm{X}$ & . & 3 & 1 & 3 \\
\hline$F_{1}$ (heterosis for yield) & . & 2 & 2 & 4 \\
\hline Parent Y & . & 1 & 3 & 3 \\
\hline
\end{tabular}

" to interpret hybrid vigour in terms only of gene interaction is a basic misconception which has contributed greatly to the present confused state of the subject" (Williams, 1959, p. 528)? This note disputes Williams' answer to the second question and endeavours to clarify his misconceptions about gene interaction and other genetical concepts such as additivity and independence.

Williams, in a simple example, shows that heterosis in the fruit yield of the tomato may be the consequence of multiplying the additively-controlled components, fruit weight and fruit number, as in table $\mathrm{r}$. Parent $\mathrm{X}$ has the greater fruit number, parent $\mathrm{Y}$ the greater fruit weight and their hybrid lies halfway in between them for each of these two characters. However, in yield, which is the product of fruit weight and fruit number, the hybrid is superior to both parents.

One genetical explanation of this heterosis is to express fruit yield as the additive combination of fruit weight and fruit number together with an additive $\times$ additive interaction between these components - the third explanation above.

A simpler genetical explanation is in terms of logarithmic values as in table 2. On this scale the two components do combine additively but their individual control is non-additive : parent $\mathrm{X}$ is partially dominant for log fruit number and parent $\mathrm{Y}$ is partially dominant for log fruit weight. Heterosis here arises from the accumulation of favourable dominants in the hybrid-the second explanation above. 
Both Williams', and our two genetical, explanations are feasible but we consider that the accumulation of favourable dominants is probably the most useful; a long history of breeding methods has been based on this hypothesis. Indeed, since the distinction between this and Williams' explanation resides in a set of log tables the introduction of his more complex explanation seems unnecessary.

However, even if Williams' explanation should prove the more useful it would not justify the nature of his attack on the gene interaction hypothesis or excuse his confusion about gene action. Our first contention is that a purely genetical explanation of these tomato yields is possible. The second is that such a genetical explanation must involve non-additivity or gene interaction, either allelic (dominance) or non-allelic (epistasis). Yet on p. 528, Williams (1959) states "The genes or gene products controlling average weight and number of fruit need not and probably do not interact in the sense that an enzyme and a precursor might interact in a synthesis. Complex characters such as yield can be based on units of the

TABLE 2

Components of log fruit yield

\begin{tabular}{|c|c|c|c|c|}
\hline & & $\begin{array}{l}\text { Component A } \\
\text { fruit number }\end{array}$ & $\begin{array}{l}\text { Component B } \\
\text { fruit weight }\end{array}$ & Yield \\
\hline Parent X & . & $0.4^{8}$ & $0 \cdot 00$ & $0 \cdot 4^{8}$ \\
\hline$F_{1}$ (heterosis for yield) & . & 0.30 & 0.30 & 0.60 \\
\hline Parent Y & . & $0 \cdot 00$ & 0.48 & $0.4^{8}$ \\
\hline
\end{tabular}

genetic system which act completely independently of one another. Interaction occurs on a higher level of organisation, among the components of the phenotype," and on p. 529, "It now seems doubtful whether an interpretation based exclusively on genetic considerations was entirely justified. ... an essentially additive genetic system conditions a multiplicative somatic basis to yield, which, when analysed as a simple character, leads erroneously to a non-additive genetic interpretation," and on p. 530, "A distinction, therefore, has to be made between gene interaction and the interrelation of the component parts of the phenotype. Phenotypic characters may be multiplicative and may consequently show a mutually dependent relationship while the gene system is strictly additive and its units are strictly independent in function."

These quotations seem to suggest that genes act and interact only below a certain level of somatic organisation and that above this level action and interaction are somatic. Instead of describing the genetics of a phenotypic character we would have to describe the genetics plus the "somatics" of the character. For tomato yield Williams places the dividing level between genetics and somatics at the components, fruit weight and fruit number. In our first quotation the dividing level is right down at the cell. This wide range of dividing level emphasises its arbitrariness. It seems immaterial to us whether interaction between gene products occurs at the enzyme level, the cell level or the level of gross phenotypic characters. The evidence for the control of log fruit yield by two independent 
partially dominant genetic systems does not reside solely in observations on fruit weight and fruit number ; it would be as apparent in log fruit yield alone after a few generations of breeding and would be equally valid and useful even if the combination of component systems took place at the cell or enzyme level. Williams is so determined to explain heterosis non-genetically that where it persists, as he has found for the yield component "fruit number" in some tomato crosses, he considers that the components may be a product of sub-units. So it may, but a theory which explains everything in this manner explains very little. To restore precision to the concepts of gene action and interaction we can hardly do better than to ignore somatics and to return to genetics alone.

The genetics of a character, whether it be enzyme or fruit yield, is determined by comparisons of the character within a breeding experiment. Gene control of a character is inferred from change associated with gene substitution. Interactive gene control is inferred when the change of character associated with a gene substitution at one locus depends on the genetic state of another locus. On these criteria Williams' tomato fruit yield is controlled partly additively and partly epistatically, the exact nature of the epistasis being specified in our fourth paragraph. Log fruit yield is controlled partly additively and partly by dominance. Both these genetic systems are precise but the latter is better-known and probably the simpler. We can see no basic misconception in attributing hybrid vigour to gene interaction.

Why then has Williams made his unnecessary attack on gene interaction? Two sources of Williams' confusion seem to be his use of the terms " independent" and " additive", as in the forms " completely independent genetic units" and " essentially additive genetic system" in the quotations above. We have pointed out that properties of genes are inferred from the phenotype by comparison of characters between individuals in a breeding experiment. In this way we may discover that the genetic control of fruit weight or of fruit number is additive but this does not imply additive control either of compounds or of sub-components of these characters. Additivity is not an absolute property of a genetic system and, in any case, the existence of " essentially additive" genetic systems at the cell level is contrary to present theories of genetic control of bio-synthesis. Additivity is a property of a genetic system only in relation to a specific character.

Similarly, if two characters are independently distributed in a population we may infer that their controlling genetic systems are independent-but only with respect to these two characters. Independence is not an absolute property of the two genetic systems : other characters controlled by them may be dependent. Indeed, the possibility of " completely independent" genetic systems coexisting in the one individual seems remote. And whether we agree or disagree with this thesis there is surely difficulty in accepting Williams' description, in our third quotation, of " mutually dependent" characters with "strictly independent" control.

Our ignorance of the determination of the phenotype is such that we cannot determine the specific section of the phenotype controlled by a specific section of the genotype. Mather (I949, p. 25) puts the matter succinctly. "It is therefore clear that while a given phenotype, taken as a whole, can be related to a given genotype, acting as a whole, . . . no similar correspondence can be expected between the parts of the phenotype 
and the parts of the genotype : the genes of a nucleus must be related in action, and the characters must be related in development." Without such a correspondence genes cannot be either "completely independent" or " essentially additive".

Williams' attempt to partition the genotype in order to justify his arbitrary separation of genetics into genetics and somatics has led to an unnecessary attack on gene interaction which only confuses the whole problem of hybrid vigour.

\title{
REFERENCES
}

GRafius, J. E. 1959. Heterosis in barley. Agron. 7., 5I, 55 I.

MATHER, K. 1949. Biometrical Genetics. Methuen, London.

williams, w. 1959. Heterosis and the genetics of complex characters. Nature, 184,527 .

\section{HETEROSIS AND THE GENETICS OF COMPLEX CHARACTERS}

\author{
WATKIN WILLIAMS \\ John Innes Institute, Bayfordbury
}

Received 3.x.6o

Dr Hayman in his comments (Hayman, I960) on my discussion of heterosis in tomato crosses (Williams, I959) is troubled primarily by the distinction that $\mathrm{I}$ attempted to draw between somatic and genetic interaction. He will apparently tolerate none other than the genetics-at-all-cost interpretation in the understanding of the biology of complex characters (para. 8) and, in taking his stand, he finds it necessary to claim exclusive rights for his own explanations of such open subjects as gene action and the absolute properties of genetic systems. Purely dialectical arguments of the kind which Hayman develops can no longer be expected to contribute materially to the advance of scientific knowledge, and, if his comments had been less obviously personal, I would have considered any form of reply as a somewhat idle exercise. In the circumstances I wish merely to point out the basic differences between Hayman's point of view and my own in our effort to provide an explanation of heterosis.

Dr Hayman appears to fail to dispute that my observations on the essential role of somatic interaction might prove more useful as a basis of understanding heterosis. He however decides to dismiss the criterion of usefulness as a measure of merit in one phrase, and elects to submerge in an inconclusive semantic discussion what is surely a most important consideration when one is attempting to rationalise such a highly intractable subject. In so doing he has tried to create the impression that ideas on heterosis which invoke considerations of somatic interaction are not only amusingly simple in theory but also useless in practice. The difficulties that have led to this curious tangle appear to stem from Dr Hayman's eagerness to include under the term gene interaction all the interacting processes of development irrespective of whether or not there is any logical reason for suspecting interactions between genes or gene products at the level of the cell. On this view gene interaction is a condition which can be inferred from analyses of weights and measurements of phenotypes 